\title{
3D numerical models of FSW processes with non-cylindrical pin
}

Philippe Bussetta ${ }^{1}$, Narges Dialami ${ }^{2}$, Michele Chiumenti $^{2}$, Carlos Agelet de Saracibar $^{2}$, Miguel Cervera $^{2}$, Romain Boman ${ }^{1}$ and Jean-Philippe Ponthot ${ }^{1 *}$

\author{
${ }^{*}$ Correspondence: \\ jp.ponthot@ulg.ac.be \\ ${ }^{1}$ University of Liège, Department \\ of Aerospace \& Mechanical \\ Engineering, Non Linear \\ Computational Mechanics, \\ Quartier Polytech 1, Allée de la \\ Découverte 13a, 4000 Liège, \\ Belgium \\ Full list of author information is \\ available at the end of the article
}

\begin{abstract}
Friction Stir Welding (FSW) process is a relatively recent welding process (patented in 1991). FSW is a solid-state joining process during which materials to be joined are not melted. During the FSW process, the behavior of the material is at the interface between solid mechanics and fluid mechanics. In this paper, a 3D numerical model of the FSW process with a non-cylindrical tool based on a solid formulation is compared to another one based on a fluid formulation. Both models use advanced numerical techniques such as the Arbitrary Lagrangian Eulerian (ALE) formulation, remeshing or the Orthogonal Sub-Grid Scale method (OSS). It is shown that these two formulations essentially deliver the same results.
\end{abstract}

Keywords: Friction Stir Welding (FSW); Finite Element Method; Remeshing; Arbitrary Lagrangian Eulerian (ALE) formalism

\section{Introduction}

Friction Stir Welding (FSW) is a relatively recent welding process, which was developed at the Welding Institute (UK) and patented in 1991 [1]. FSW is a solid-state joining process. It means that during welding the materials to be joined are not melted. The joining is constituted by mechanical intermixing of the two materials. A rotating non-consumable tool is inserted between the two work-pieces and displaced along the welding direction (see Figure 1). The tool is composed of two parts: a pin and a shoulder. The pin is introduced into the welded joint to mix deeply the two materials together. The aim of the shoulder is to contain the material around the pin. The part of the welding joint where the velocity of the tool and the advancing velocity add up is named the advancing side. The other part, where the two velocities are in opposite directions, is called the retreating side. The friction between the rotating tool and the work-pieces as well as the plastic deformation in the neighborhood of the tool increase the temperature in the welded zone and thus soften the materials. But, during the process, the temperature is always smaller than the melting temperature of the materials. So, the heat-affected zone is smaller and the quality of the welding is higher than in more classical welding processes. In spite of the important number of applications of FSW, the phenomena happening during welding are still not very well understood. Therefore, the investigations on this process and especially regarding numerical simulations are still very active [2-8]. The mechanical intermixing induces very high strains in the material in the neighborhood of the tool. Using a classical Lagrangian formulation as it is generally 
the case in solid mechanics would thus inevitably lead to mesh distorsions. Consequently, classical numerical simulation techniques have to be extended in order to track the correct material deformations. One of the possibilities is to use the Arbitrary Lagrangian Eulerian (ALE) formulation [3, 9-11]. This formulation is used to keep the mesh motion under control regardless of the real material displacements. The ALE formulation is also used to maintain a good mesh quality during the computation. This paper presents and compares two different 3D numerical models of the FSW process. The first model is based on a solid approach written in terms of nodal positions and nodal temperatures. The second model is based on a fluid approach written in terms of the velocity, the pressure and the temperature fields. Both models use advanced numerical techniques such as remeshing and the ALE formulation. A 2D numerical model of the FSW process for each approach has already been presented in [6].

\section{D Numerical modeling of FSW process}

To model this welding process, the displacement of the tool is split into an advancing movement (actually assigned to the work-pieces but, in the opposite direction) and

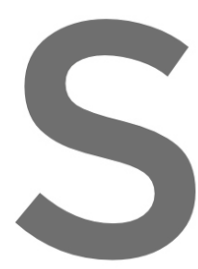

a rotation (in
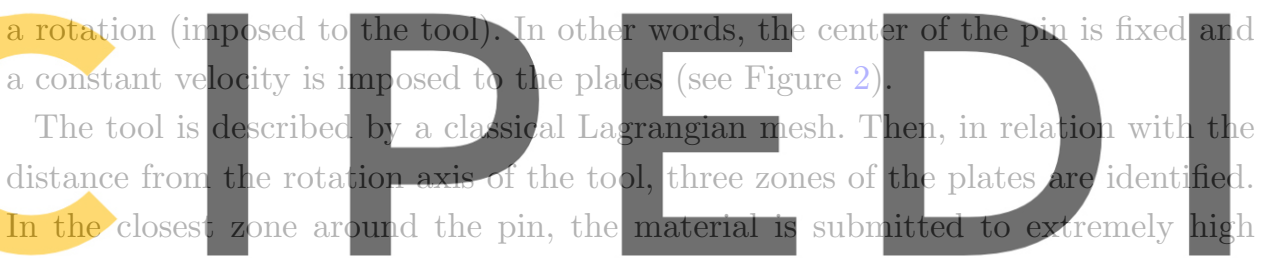

strains. This region is a part of the thermo-mechanically affected zone (TMAZ). In

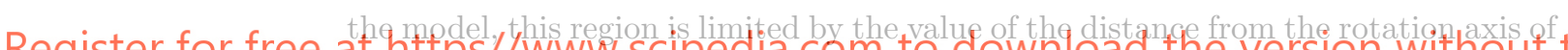

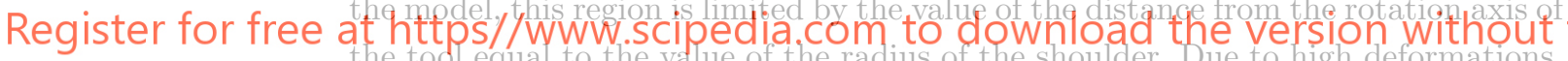

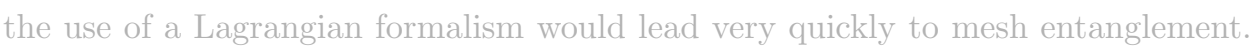

Thus, in this region, the ALE formulation is employed. On top of this, the ALE formulation allows the model to take into account tools with no rotational symmetry. In this zone, the mesh has the same rotational speed as the tool (red region in Figure 3). In the furthest zone from the tool, the grey zone in Figure 3, the Eulerian formulation is used. Thus in this region, the mesh is fixed. The ring connecting region 1 and region 3 is a transition zone (white region numbered 2 in Figure 3 ). In such a model, the quality of the mesh does not change during the simulation except in the transition zone. So, to overcome this problem, two different numerical techniques are proposed (see section The transition zone).

\section{Thermomechanical formulation}

The numerical models presented here are based on the finite element method. In this paper, two numerical formulations are compared. The first one is based on a solid mechanics approach. It is written in terms of nodal positions and temperatures. The second one is based on a fluid mechanics approach. The equilibrium is written as a function of nodal velocities, pressures and temperatures.

\section{Solid approach}

In the solid approach, the finite elements are linear hexahedra. The position and temperature fields are computed at each node of the elements. The stresses and the 
internal variables are computed at each quadrature point of the element (8 Gauss points). To overcome the locking phenomenon, the pressure is considered constant over the element and computed only at a central quadrature point. The thermomechanical equations are split into a mechanical part and a thermal part. At each time step, the mechanical equations are first solved using a constant temperature field. This temperature field is the one obtained at the previous increment. Then, the thermal equations are solved on the frozen resulting geometrical configuration that has just been obtained.

\section{Fluid approach}

The fluid approach is based on a stabilized mixed linear temperature-velocitypressure finite element formulation. This formulation is stabilized adopting the Orthogonal Sub-Grid Scale method (OSS) [12-14] to solve both the pressure instability induced by the incompressibility constraint and the instabilities coming from the convective term. A tetrahedral mesh is used for the domain discretization. The velocity, the pressure and the temperature fields are computed at each node of the elements. The deviatoric stresses and the other internal variables are computed
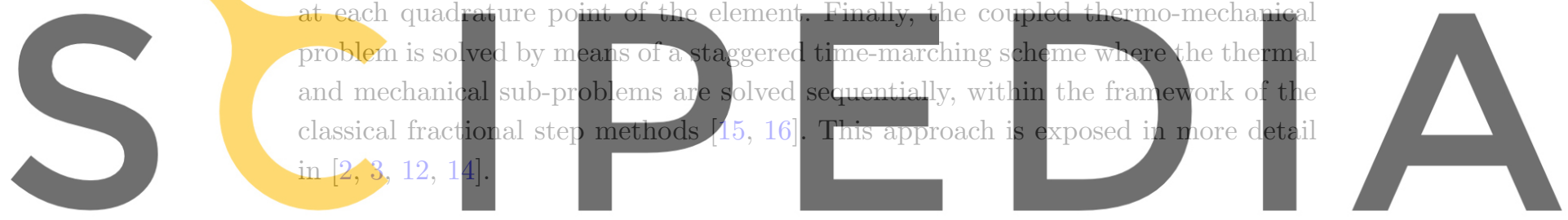

Numerical simulation strategy

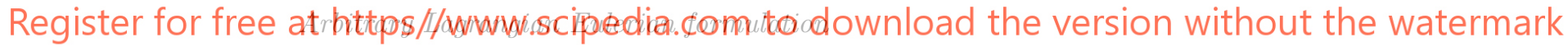

In region 1 and region 3 in Figure 3 the ALE formulation is used. Indeed, the Eule-

rian formulation (used in the region 3) is a particular case of the ALE formulation.

In the ALE formalism, unlike in the Lagrangian case which is commonly used in solid mechanics, the mesh no longer follows the material motion [2, 3, 9-11]. Consequently, a new grid coordinate system $R_{\vec{\chi}}$ is defined and the conservation laws able to describe the FSW process are rewritten in terms of the new coordinates $\vec{\chi}$ : Mass:

$$
\left.\frac{\partial \rho}{\partial t}\right|_{\vec{\chi}}+\overrightarrow{\boldsymbol{c}} \cdot \vec{\nabla} \rho+\rho \vec{\nabla} \cdot \overrightarrow{\boldsymbol{v}}=0
$$

Momentum:

$$
\rho\left(\left.\frac{\partial \overrightarrow{\boldsymbol{v}}}{\partial t}\right|_{\vec{\chi}}+(\overrightarrow{\boldsymbol{c}} \cdot \vec{\nabla}) \overrightarrow{\boldsymbol{v}}\right)=\vec{\nabla} \cdot \boldsymbol{\sigma}+\rho \overrightarrow{\boldsymbol{b}}
$$

Energy:

$$
\rho C_{p}\left(\left.\frac{\partial T}{\partial t}\right|_{\vec{\chi}}+\overrightarrow{\boldsymbol{c}} \cdot \vec{\nabla} T\right)=D_{m e c h}-\vec{\nabla} \cdot \overrightarrow{\boldsymbol{q}}
$$

where $\rho$ and $C_{p}$ are the mass density and the specific heat capacity, $\boldsymbol{\sigma}$ is the Cauchy stress tensor, $\overrightarrow{\boldsymbol{b}}$ is the specific body forces, $T$ is the temperature, $D_{m e c h}$ is the plastic 
dissipation rate per unit of volume. The heat flux, $\overrightarrow{\boldsymbol{q}}$, is defined according to the isotropic Fourier's law as:

$$
\overrightarrow{\boldsymbol{q}}=-k \vec{\nabla} T
$$

The convective velocity $\overrightarrow{\boldsymbol{c}}=\overrightarrow{\boldsymbol{v}}-\overrightarrow{\boldsymbol{v}^{*}}$ is the difference between the material velocity $\overrightarrow{\boldsymbol{v}}$ and the mesh velocity $\overrightarrow{\boldsymbol{v}^{*}}$. Both the stress tensor, $\boldsymbol{\sigma}$, and the strain rate tensor, $\boldsymbol{D}$, are split into volumetric and deviatoric parts:

$$
\boldsymbol{\sigma}=p \boldsymbol{I}+\boldsymbol{S}
$$
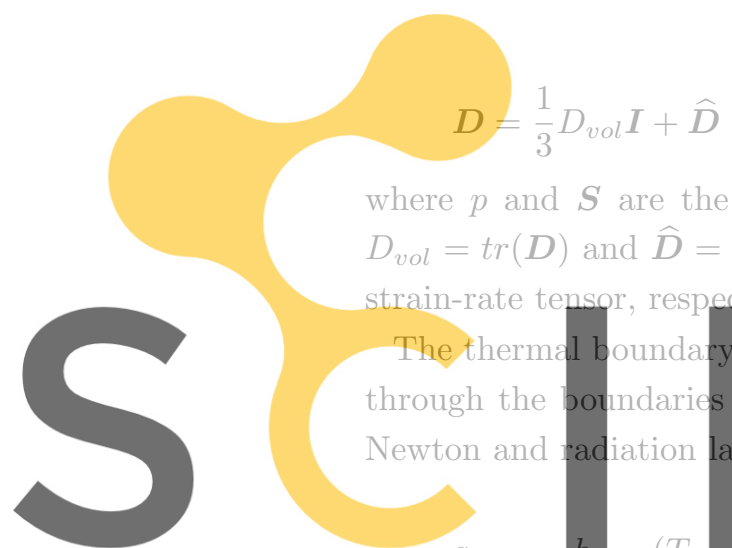

where $p$ and $S$ are the pressure and the stress deviator, respectively. Similarly, $D_{\text {vol }}=\operatorname{tr}(\boldsymbol{D})$ and $\widehat{D}=\operatorname{dev}(\boldsymbol{D})$ are the volumetric and the deviatoric parts of the
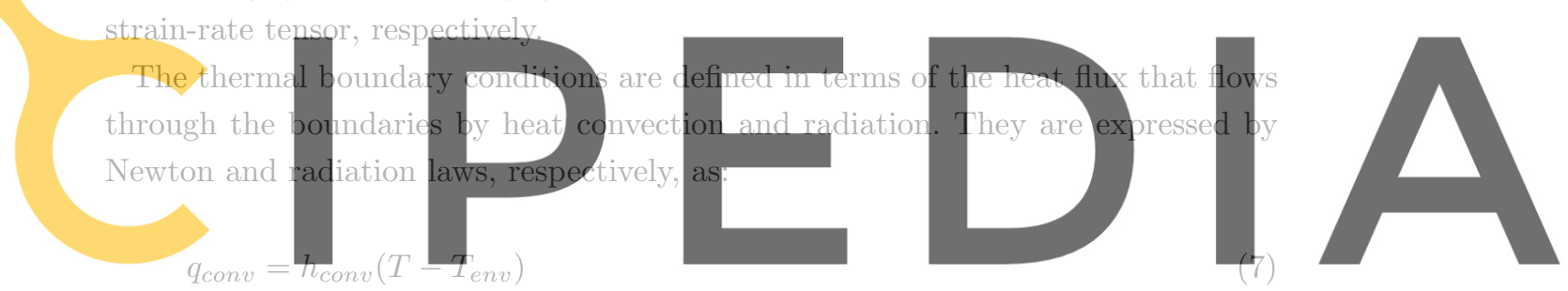

\section{Register for free at https//www.scipedia.com to download the version without the watermark}

$$
q_{\text {rad }}=\sigma_{0} \varepsilon\left(T^{4}-T_{\text {env }}^{4}\right)
$$

where $h_{\text {conv }}$ is the heat transfer coefficient by convection, $\sigma_{0}$ is the Stefan-Boltzmann constant and $\varepsilon$ is the emissivity factor. Finally, $T_{\text {env }}$ is the surrounding environment temperature.

The ALE formulations used in the two approaches are different.

Solid approach The ALE formulation used in the solid approach is described in more details in [9-11]. To simplify the solution procedure and remain competitive against Lagrangian models, the system of ALE equations (equations 1 to 3 ) is solved using an operator-split procedure. First, for each time step, the classical Lagrangian thermomechanically coupled formalism is used. During this Lagrangian step the mesh sticks to the material $\left(\overrightarrow{\boldsymbol{v}^{*}}=\overrightarrow{\boldsymbol{v}}, \overrightarrow{\boldsymbol{c}}=\overrightarrow{\mathbf{0}}\right)$ until an equilibrated Lagrangian configuration is iteratively obtained. So, the weak form of the governing equations which are solved during this first step is defined over the current integration domain $\Omega$ and its boundary $\partial \Omega$ (see equations 9 and 10). Let us assume that the boundary $\partial \Omega$ can be split into $\partial \Omega_{\sigma}$ and $\partial \Omega_{u}$, being $\partial \Omega=\partial \Omega_{\sigma} \cup \partial \Omega_{u}$ such that tractions are prescribed on $\partial \Omega_{\sigma}$ while displacements are specified on $\partial \Omega_{u}$, respectively. In a similar way, boundary $\partial \Omega$ can be also split into $\partial \Omega_{q}$ and $\partial \Omega_{\theta}$ such that $\partial \Omega=$ $\partial \Omega_{q} \cup \partial \Omega_{\theta}$, where fluxes (on $\partial \Omega_{q}$ ) and temperatures (on $\partial \Omega_{\theta}$ ) are prescribed for the 
heat transfer analysis.

$$
\begin{aligned}
\int_{\Omega}\left(\rho \frac{d^{2} \overrightarrow{\boldsymbol{u}}}{d t^{2}} \cdot \delta \overrightarrow{\boldsymbol{u}}\right) d V= & \int_{\Omega}(\rho \overrightarrow{\boldsymbol{b}} \cdot \delta \overrightarrow{\boldsymbol{u}}) d V-\int_{\Omega}(\boldsymbol{\sigma}: \vec{\nabla} \delta \overrightarrow{\boldsymbol{u}}) d V+\int_{\partial \Omega_{\sigma}}(\overrightarrow{\boldsymbol{t}} \cdot \delta \overrightarrow{\boldsymbol{u}}) d S \\
\int_{\Omega}\left(\rho C_{p} \frac{d T}{d t} \delta T\right) d V & +\int_{\Omega}[k \vec{\nabla} T \cdot \vec{\nabla}(\delta T)] d V \\
& =\int_{\Omega}\left(D_{m e c h} \delta T\right) d V-\int_{\partial \Omega_{q}}\left[\left(q_{\text {conv }}+q_{r a d}\right) \delta T\right] d S
\end{aligned}
$$

where $\delta \vec{u}$ and $\delta T$ are the test functions of the displacement and temperature fields. $\vec{t}$ is prescribed tractions on the boundary domain $\partial \Omega_{\sigma}$.

The second step, also called the Eulerian step, is divided into two substeps: first the nodes of the mesh are relocated to a more suitable position, thus defining a new mesh with the same topology and the mesh velocity $\overrightarrow{v^{*}}$. In the case of region 1 and region 3 the position of the relocated nodes is known because the mesh velocity of these regions is imposed. Then, the unknowns and the internal variables are
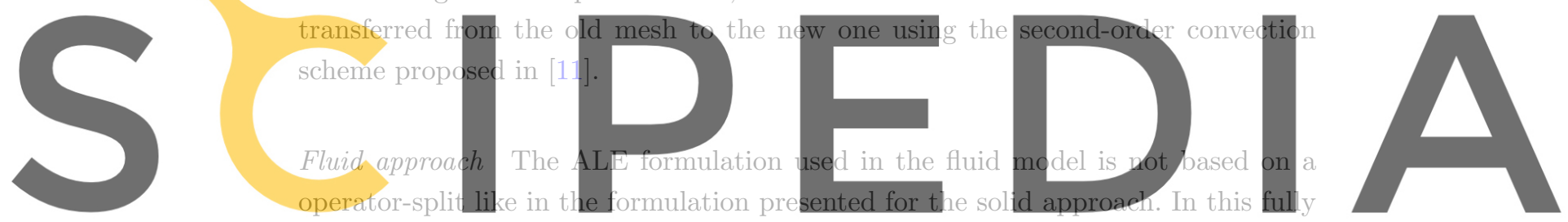

coupled formulation [2,3], the equilibrium state is computed at each time increment

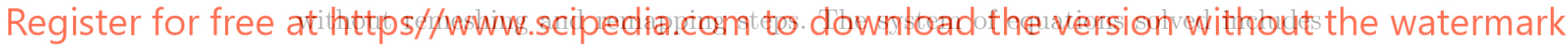

the convective terms due to the velocity of the mesh relative to the material. In the

TMAZ, region 1 in Figure 3, the velocity of the mesh is imposed and the velocity and the pressure of the material are directly computed. In the case of the Eulerian formulation (region 3 in Figure 3), the mesh does not move during the computation. The following assumptions are considered for the numerical simulation of the FSW process (more detail can be found in $[2,3]$ ):

- The flow is assumed to be incompressible as the volumetric changes including thermal deformation are found to be negligible, $D_{v o l}=\vec{\nabla} \cdot \overrightarrow{\boldsymbol{v}} \cong 0$.

- Therefore, the deviatoric part of total strain rate tensor, $\widehat{D}$, is computed as the symmetric part of the velocity gradient as: $\widehat{\boldsymbol{D}}=\operatorname{dev}(\dot{\boldsymbol{\varepsilon}})=\vec{\nabla}^{s} \overrightarrow{\boldsymbol{v}}$.

- Due to the very high viscosity of the material, the material flow is characterized by very low values of Reynolds number $(R e<<1)$. This is the reason why, in the balance of momentum equation, the inertia term can be neglected.

The governing equations which are used to describe the thermo-mechanical problem able to describe the FSW process are: the mass conservation (equation 1), the balance of momentum equation (equation 2) and the balance of energy equation (equation 3). Taking into account the previous assumptions, these governing equations can be rewritten:

Mass:

$$
\vec{\nabla} \cdot \vec{v}=0
$$


Momentum:

$$
\vec{\nabla} \cdot S+\vec{\nabla} p+\rho \overrightarrow{\boldsymbol{b}}=0
$$

Energy:

$$
\rho C_{p}\left(\left.\frac{\partial T}{\partial t}\right|_{\vec{\chi}}+\overrightarrow{\boldsymbol{c}} \cdot \vec{\nabla} T\right)=D_{m e c h}-\vec{\nabla} \cdot \overrightarrow{\boldsymbol{q}}
$$

The weak form of these equations is defined over the integration domain $\Omega$ and its boundary $\partial \Omega$ (see equations 14, 15 and 16). Let us assume that the boundary $\partial \Omega$ can be split into $\partial \Omega_{\sigma}$ and $\partial \Omega_{v}$, being $\partial \Omega=\partial \Omega_{\sigma} \cup \partial \Omega_{v}$ such that tractions are prescribed on $\partial \Omega_{\sigma}$ while velocities are specified on $\partial \Omega_{v}$, respectively. In a similar way, boundary $\partial \Omega$ can be also split into $\partial \Omega_{q}$ and $\partial \Omega_{\theta}$ such that $\partial \Omega=\partial \Omega_{q} \cup \partial \Omega_{\theta}$, where fluxes (on $\partial \Omega_{q}$ ) and temperatures (on $\partial \Omega_{\theta}$ ) are prescribed for the heat transfer analysis.

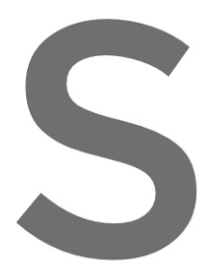

$$
\int_{\Omega}[(\vec{\nabla} \cdot \vec{v}) \delta p] d V=0
$$
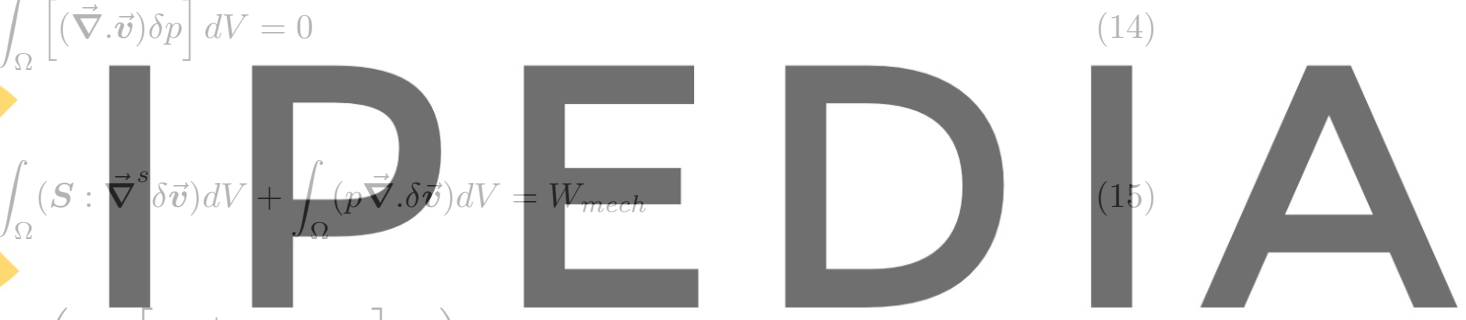

Register for free at https//www.seipedia.com to download the version without the watermark

where $\delta \vec{v}, \delta p$ and $\delta T$ are the test functions of the velocity, pressure and temperature fields, respectively while the mechanical and the thermal work are defined as:

$$
\begin{aligned}
& W_{\text {mech }}=\int_{\Omega}(\rho \overrightarrow{\boldsymbol{b}} . \delta \overrightarrow{\boldsymbol{v}}) d V+\int_{\partial \Omega_{\sigma}}(\overrightarrow{\boldsymbol{t}} . \delta \overrightarrow{\boldsymbol{v}}) d S \\
& W_{\text {ther }}=\int_{\Omega}\left(D_{\text {mech }} \delta T\right) d V-\int_{\partial \Omega_{q}}\left[\left(q_{\text {conv }}+q_{\text {rad }}\right) \delta T\right] d S
\end{aligned}
$$

where $\overrightarrow{\boldsymbol{t}}$ is prescribed tractions on the boundary domain $\partial \Omega_{\sigma}$.

The transition zone

Solid approach In the solid approach, the transition zone is a ring with a finite thickness (region 2 in Figure 3). In this region, the evolution of the rotational speed of the mesh, which differs from the material velocity, is linearly interpolated between the ALE region and the Eulerian zone. As the mesh distortion grows with time, a remeshing operation is periodically required. For one full rotation of the pin, the remeshing process is applied 30 times. The time interval between two successive remeshings is thus constant. The remeshing operation can be divided into two steps. First, a better-suited mesh, called the new mesh, is created. In the case of the transition zone, the relatively simple geometry of this region allows an easy generation of the new hexahedral mesh. Then, to carry on the computation over 
this mesh, the state variables from the mesh before remeshing, called the old mesh, has to be transferred to the new one. Each field used to define the equilibrium state is transferred independently from the other ones. The data transfer method used in this paper is called the Finite Volume Transfer Method with linear reconstruction of the fields (FVTM-LR). In [17], this transfer method is presented in more details and the comparison with some of the remapping algorithms most commonly used in the literature brings to light the advantages of this method.

Fluid approach In the fluid model the transition zone (region 2 in Figure 3) is limited to a circle (zero thickness). Each node of the mesh on this circle is duplicated. One node is linked to the ALE region (numbered 1) and the other one to the Eulerian region (numbered 3). The coupling between both regions is performed using a specific node-to-node link approach. At every mesh movement step, for a given node of the ALE region, the corresponding node of the Eulerian one is found and a link between the two nodes is created. Afterwards, the boundary conditions and the properties of the nodes of the region 3 are copied to the corresponding nodes of the region 1 within the link. The time step can be conveniently chosen

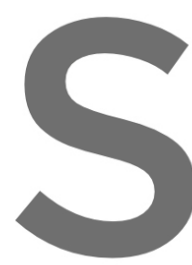

such that the two interace meshes (ALH and Eulerian)

this case the

the next one

Thermomechanical constitutive model
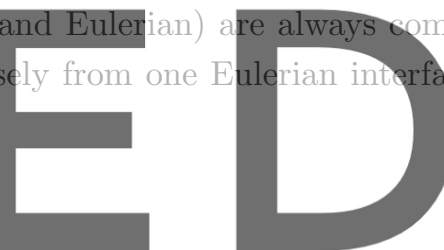

In both models, the constitutive model of the tool is thermo-rigid. So, no mechan-

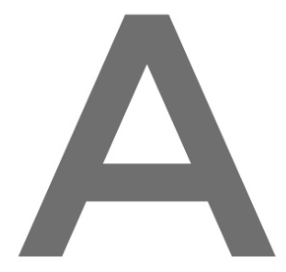

Register for free at https//www.scipedia.com to download the version without the watermark thermal equations, the tool has a classical thermal behaviour as far as heat con-

duction is concerned. In addition, the material behavior of the plates is modeled as thermo-visco-plastic using a Norton-Hoff constitutive model:

$$
\boldsymbol{S}=2 \mu(T) \widehat{\boldsymbol{D}}\left(\sqrt{3} \sqrt{\frac{2}{3} \widehat{\boldsymbol{D}}: \widehat{\boldsymbol{D}}}\right)^{m(T)-1}
$$

where $m$ and $\mu$ are the rate sensitivity and viscosity parameters respectively. Both are temperature dependent.

In the FSW process, the heat is mostly generated by the mechanical dissipation, which is computed as a function of the plastic strain rate and the deviatoric stresses as:

$$
D_{\text {mech }}=\gamma \boldsymbol{S}: \widehat{\boldsymbol{D}}
$$

where $\gamma \approx 0.9$ is the fraction of the total plastic energy converted into heat.

Solid approach In the solid model, the value of the variation of the pressure $(d p)$ is computed thanks to the variation of the volume $(d V)$ and the bulk modulus $(K): d p=K d V$. In addition, with the solid approach, it is possible to replace the Norton-Hoff constitutive model with a thermo-elasto-visco-plastic one, see e.g. [18]. With this kind of constitutive model, it is possible to compute the residual stresses. 
Fluid approach In the fluid model, the material is assumed to be incompressible and this constraint is incorporated into the equations to be solved.

\section{Thermomechanical contact}

Solid approach In the solid model, a perfect sticking thermomechanical contact is considered between the tool and the work-piece. It means that the temperature field and the displacement field are continuous through the interface between the tool and the work-piece.

Fluid approach The heat flux is also produced by the friction between pin and the work-piece. This heat flux can be expressed using the Norton's friction model. The heat generated by friction is split into a part absorbed by the pin (noted $q_{\text {frict }}^{\text {pin }}$ ) and another one absorbed by the work-piece (noted $\left.q_{\text {frict }}^{S Z}\right)$ :
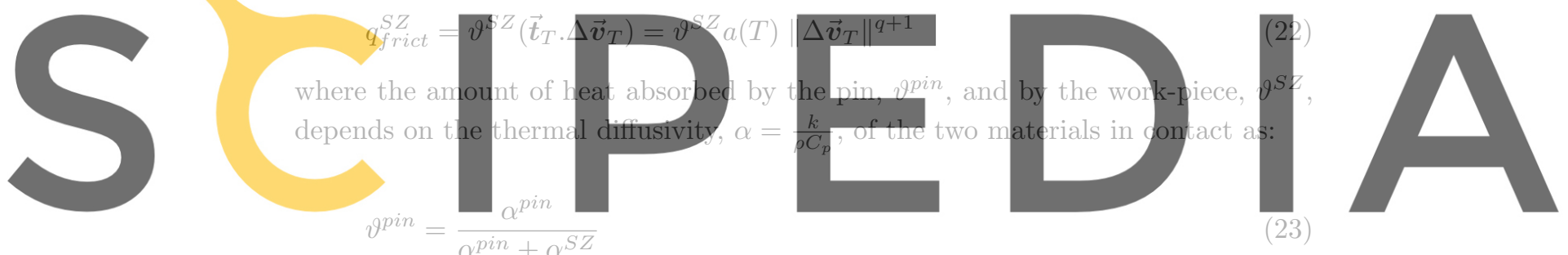

Register for free at https//www.scipedia.com to download the version without the watermark

$$
v^{S Z}=\frac{\alpha^{S Z}}{\alpha^{p i n}+\alpha^{S Z}}
$$

The tangential component of the traction vector at the contact interface, $\overrightarrow{\boldsymbol{t}}_{T}$, is defined as:

$$
\overrightarrow{\boldsymbol{t}}_{T}=a(T)\left\|\Delta \overrightarrow{\boldsymbol{v}}_{T}\right\|^{q} \overrightarrow{\boldsymbol{u}}_{T}
$$

where $a(T)$ is the (temperature dependent) material consistency, $0 \leq q \leq 1$ is the strain rate sensitivity and $\overrightarrow{\boldsymbol{u}}_{T}=\frac{\Delta \overrightarrow{\boldsymbol{v}}_{T}}{\left\|\Delta \overrightarrow{\boldsymbol{v}}_{T}\right\|}$ is the tangential unit vector, defined in terms of the relative tangential velocity at the contact interface, $\overrightarrow{\boldsymbol{v}}_{T}$.

\section{Comparison of numerical results}

In this paper, the numerical results of the solid approach are compared with the already validated model based on the fluid approach (see $[2,3,7,8]$ ). In this example, the section of the pin is an equilateral triangle (Figures 4 and 5). The dimensions of the tool are presented in Figure 4. The width of the two plates is $50 \mathrm{~mm}$, the thickness is $4.7 \mathrm{~mm}$ and the simulated length is $100 \mathrm{~mm}$. The rotation axis of the tool is located at the center of the simulated region (see Figure 5).

The most important parameters of the considered FSW process are the rotation speed (40 RPM or $100 \mathrm{RPM}$ ) and the welding speed (400 $\mathrm{mm} \mathrm{min}^{-1}$ ). The thermomechanical properties of the plates are the following: 
- density: $2700 \mathrm{~kg} \mathrm{~m} \mathrm{~m}^{-3}$

- bulk modulus: $69 \mathrm{GPa}$ (used only with the solid approach)

- thermo-mechanical Norton-Hoff law (presented in the page 7)

with $\mu=100 M P a, m=0.12$,

- heat conductivity: $120 \mathrm{~W} \mathrm{~m}^{-1} \mathrm{~K}^{-1}$

- thermal expansion coefficient: $1 \times 10^{-6} K^{-1}$

- heat capacity: $875 \mathrm{~J} \mathrm{~kg}^{-1} \mathrm{~K}^{-1}$

The thermo-mechanical properties of the tool are the following:

- density: $7800 \mathrm{~kg} \mathrm{~m}^{-3}$;

- heat conductivity: $43 \mathrm{~W} \mathrm{~m}^{-1} \mathrm{~K}^{-1}$;

- heat capacity: $460 \mathrm{~J} \mathrm{~kg}^{-1} \mathrm{~K}^{-1}$

During all the computation, the room temperature is considered constant at $20^{\circ} \mathrm{C}$.

The thermal boundary conditions of this problem are the following (heat transfer is neglected along the external perimeter of the two plates):

- Conduction on the lower side of both plates (approximation of the thermal behavior of the backing plate), exchange coefficient: $4500 \mathrm{~W} \mathrm{~m}^{-2} \mathrm{~K}^{-1}$;

- Convection and radiation on the free upper side of both plates (except the part

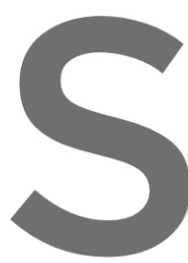

in cont
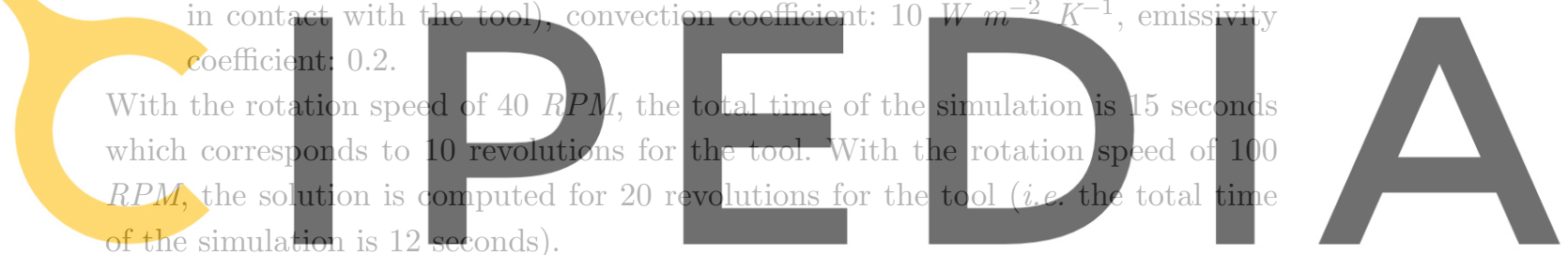

Figures 6 to 9 show the evolution of the pressure and the evolution of the tem-

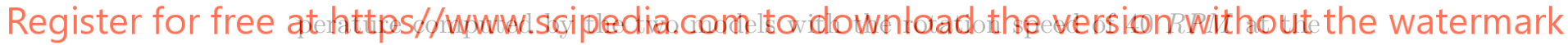

control points and along the control line defined in Figure 5. Figures 10 to 13 present

the same comparison with the rotation speed of 100 RPM. Points 1 and 2 have the same rotational speed as the tool (these points move according to the mesh). Point 3 is fixed in space.

After a transient phase which depends on the numerical strategy adopted for each approach the results of both models are very similar for the two values of the rotation speed of the tool (see Figures 6 to 8 and 10 to 12). The difference of frequency between the pressure at point 3 and the pressure and the temperature at points 1 and 2 is explained by the fact that point 3 is fixed in space while points 1 and 2 have the same rotational velocity as the tool. On the one hand, the pressure at point 3 is affected by the three corners of the pin. On the other hand, the frequency of the pressure and the temperature at points 1 and 2 are controlled by the rotation speed of the tool. Consequently, the pressure frequency at point 3 is three times higher than the frequency of the pressure or the temperature at points 1 or 2 .

In addition, the temperature field is a good indicator of the mechanical intermixing of the material. The small differences between the values of the temperature fields along the control line (Figures 9 and 13) show that the two models essentially deliver the same results. Moreover, the value of the pressure field is similar around the tool (see Figure 9 and 13). These comparisons with two values of the rotation speed of the tool prove that the solid and the fluid models essentially deliver the same results as far as the temperature field and the pressure field prediction during welding are concerned. 


\section{Conclusion}

The phenomena happening during the Friction Stir Welding (FSW) process are at the interface between solid mechanics and fluid mechanics. In this paper, two different formulations are presented to simulate the FSW process numerically. One 3D model is based on a solid approach which computes the position and the temperature fields and another one is based on a fluid approach written in terms of velocity, pressure and temperature fields. Both models use advanced numerical techniques such as the Arbitrary Lagrangian Eulerian formalism or remeshing operations or an advanced stabilization algorithm. These advanced numerical techniques allow the simulation of the FSW process with a tool with no rotational symmetry. The aim of the paper is to compare two computational models based respectively on a solid and a fluid approach for the solution of FSW process. Based on the authors' point of view, being able to simulate a process using a solid model and at the same time a fluid model, is numerically very interesting and represents a further verification of the implementation in both approaches. The presented example (with a triangular pin) shows that the two formulations essentially deliver the same results. More investigations are still needed to understand the small differences between the two

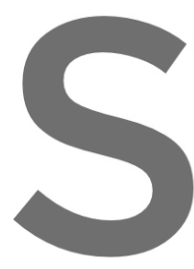
models. While the fluid
the model based on th
compute the residual
replaced with a thermo-
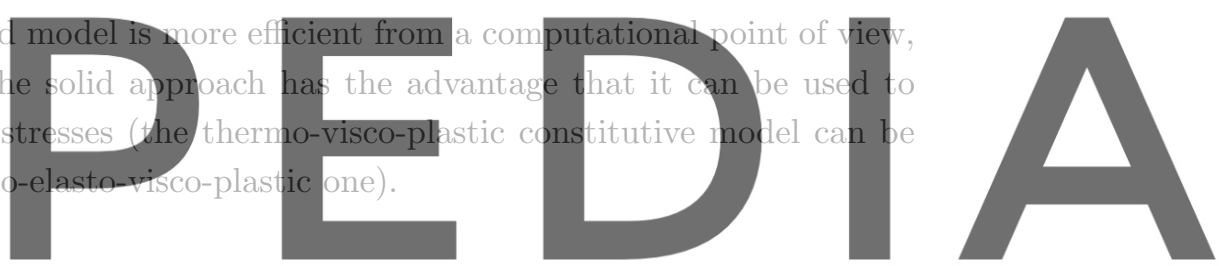

Competing interests

The authors declare that they have no competing interests

Register for free at https/fwww.scipedia.com to download the version without the watermark

The Belgian authors worked on the model based on the solid approach and the Spanish authors worked on the one based on the fluid approach. All authors have read and approved the final manuscript.

\section{Acknowledgments}

The Belgian authors wish to acknowledge the Walloon Region for its financial support to the STIRHETAL project (WINNOMAT program, convention number 0716690) and to the FSW-PME project (Programme de recherche collective 2013 - convention number 1217826) in the context of which this work was performed.

\section{Author details}

${ }^{1}$ University of Liège, Department of Aerospace \& Mechanical Engineering, Non Linear Computational Mechanics, Quartier Polytech 1, Allée de la Découverte 13a, 4000 Liège, Belgium. ${ }^{2}$ International Centre for Numerical Methods in Engineering (CIMNE), Universidad Politécnica de Cataluña, Campus Norte UPC, 08034 Barcelona, Spain.

\section{References}

1. Thomas, W.M., Nicholas, E.D.: Friction stir welding for the transportation industries. Materials and Design 18(4-6), 269-273 (1997). doi:10.1016/S0261-3069(97)00062-9

2. Dialami, N., Chiumenti, M., Cervera, M., Agelet de Saracibar, C.: An apropos kinematic framework for the numerical modelling of friction stir welding. Computers and Structures 117, 48-57 (2013). doi:10.1016/j.compstruc.2012.12.006

3. Chiumenti, M., Cervera, M., Agelet de Saracibar, C., Dialami, N.: Numerical modeling of friction stir welding processes. Computer Methods in Applied Mechanics and Engineering 254, 353-369 (2013). doi:10.1016/j.cma.2012.09.013

4. Assidi, M., Fourment, L., Guerdoux, S., Nelson, T.: Friction model for friction stir welding process simulation: Calibrations from welding experiments. International Journal of Machine Tools and Manufacture 50(2), 143-155 (2010). doi:10.1016/j.ijmachtools.2009.11.008

5. Dialami, N., Chiumenti, M., Cervera, M., Agelet de Saracibar, C., Ponthot, J.P.: Material flow visualization in friction stir welding via particle tracing. International Journal of Material Forming (2013). doi:10.1007/s12289-013-1157-4

6. Bussetta, P., Dialami, N., Boman, R., Chiumenti, M., Agelet de Saracibar, C., Cervera, M., Ponthot, J.-P.: Comparison of a fluid and a solid approach for the numerical simulation of Friction Stir Welding with a non-cylindrical pin. Steel Research International 85, 968-979 (2014). doi:10.1002/srin.201300182

7. Santiago, D., Lombera, G., Urquiza, S., Agelet de Saracibar, C., Chiumenti, M.: Modelado termo-mecánico del proceso de friction stir welding utilizando la geometría real de la herramienta. Revista Internacional de Métodos Numéricos para Cálculo y Diseño en Ingeniería 26, 293-303 (2010) 
8. Agelet de Saracibar, C., Chiumenti, M., Cervera, M., Dialami, N., Seret, A.: Computational modeling and sub-grid scale stabilization of incompressibility and convection in the numerical simulation of friction stir welding processes. Archives of Computational Methods in Engineering 21(1), 3-37 (2014). doi:10.1007/s11831-014-9094-z

9. Donea, J., Huerta, A., Ponthot, J.-P., Rodríguez-Ferran, A.: Arbitrary Lagrangian Eulerian Methods. In: Stein, E., de Borst, R., Hughes, T.J.R. (eds.) Encyclopedia of Computational Mechanics. John Wiley \& Sons, Ltd, New York (2004). doi:10.1002/0470091355.ecm009

10. Boman, R., Ponthot, J.-P.: Efficient ALE mesh management for 3D quasi-eulerian problems. International Journal for Numerical Methods in Engineering 92, 857-890 (2012). doi:10.1002/nme.4361

11. Boman, R., Ponthot, J.-P.: Enhanced ALE data transfer strategy for explicit and implicit thermomechanical simulations of high-speed processes. International Journal of Impact Engineering 53, 62-73 (2013). doi:10.1016/j.ijimpeng.2012.08.007

12. Agelet de Saracibar, C., Chiumenti, M., Valverde, Q., Cervera, M.: On the orthogonal subgrid scale pressure stabilization of finite deformation J2 plasticity. Computer Methods in Applied Mechanics and Engineering 195, 1224-1251 (2006). doi:10.1016/j.cma.2005.04.007

13. Cervera, M., Chiumenti, M., Valverde, Q., Agelet de Saracibar, C.: Mixed linear/linear simplicial elements for incompressible elasticity and plasticity. Computer Methods in Applied Mechanics and Engineering 192, 5249-5263 (2003)

14. Chiumenti, M., Valverde, Q., Agelet de Saracibar, C., Cervera, M.: A stabilized formulation for incompressible plasticity using linear triangles and tetrahedra. International Journal of Plasticity 20, 1487-1504 (2004). doi:10.1016/j.ijplas.2003.11.009

15. Agelet de Saracibar, C., Cervera, M., Chiumenti, M.: On the formulation of coupled thermoplastic problems with phase-change. International Journal of Plasticity 15, 1-34 (1999)

16. Cervera, M., Agelet de Saracibar, C., Chiumenti, M.: Thermo-mechanical analysis of industrial solidification processes. International Journal for Numerical Methods in Engineering 46, 1575-1591 (1999)

17. Bussetta, P., Boman, R., Ponthot, J.-P.: Efficient 3D data transfer operators based on numerical integration. International Journal for Numerical Methods in Engineering 102(3-4), 892-929 (2015). doi:10.1002/nme.4821

18. Ponthot, J.P.: Unified stress update algorithms for the numerical simulation of large deformation elasto-plastic and elasto-viscoplastic processes. International Journal of Plasticity 18, 91-126 (2002). doi:10.1016/S0749-6419(00)00097-8

Figures

Figure 1 Scheme of the FSW process

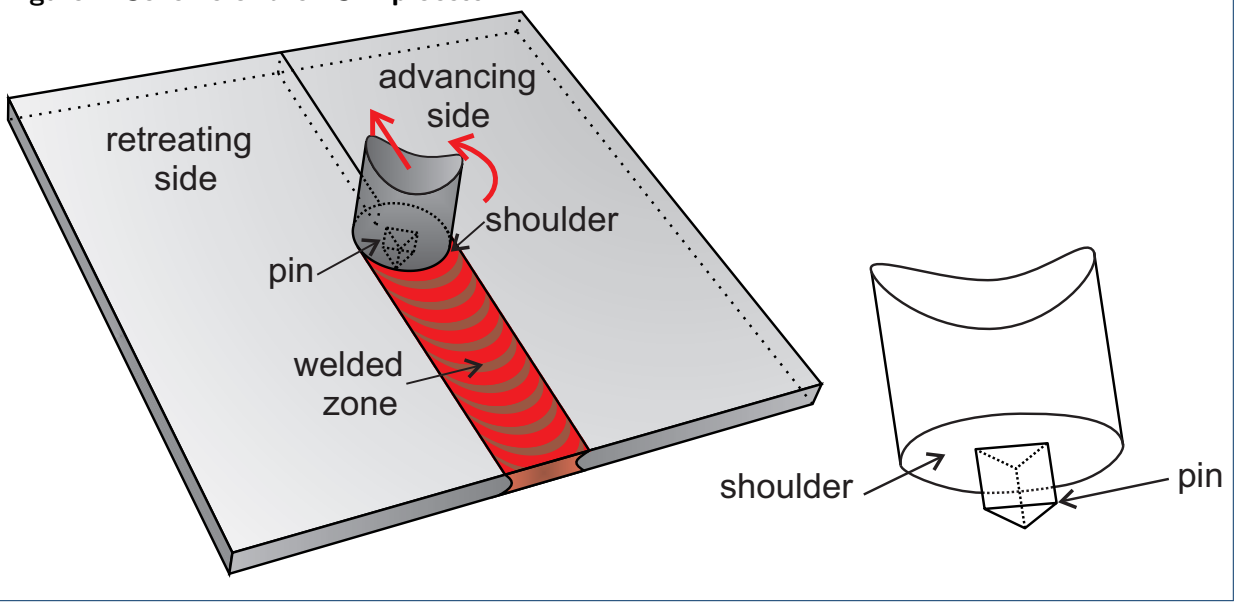


Figure 2 Scheme of the FSW model. A rotation is imposed to the pin (blue arrow) while the advancing velocity of the pin is replaced by a velocity imposed to the plates in the opposite direction (red arrows).

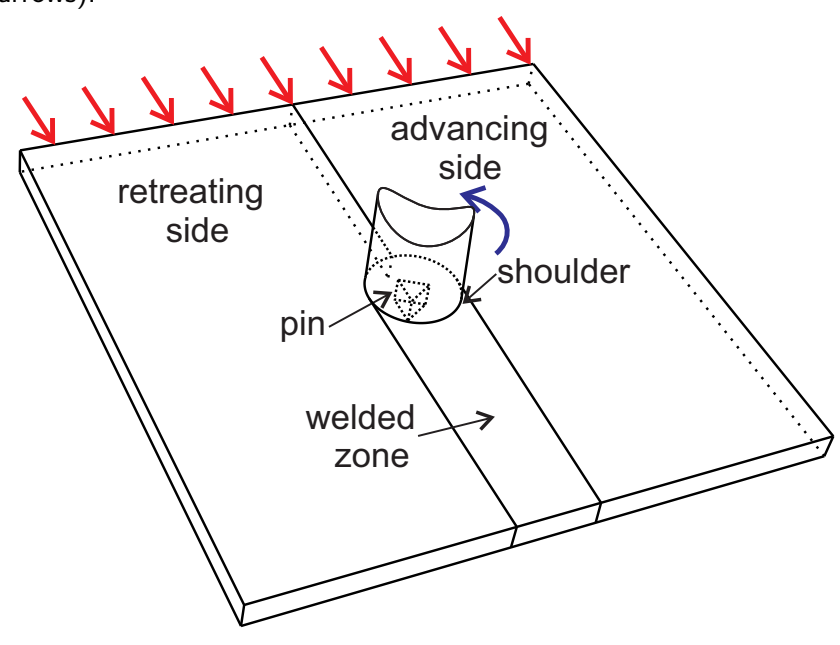

Figure 3 Scheme of the different zones of the numerical model. The different zones of the model: ALE formulation is used on the red region (1), the transition zone corresponds to the white region (2), and the Eulerian formulation is applied on the grey region (3)

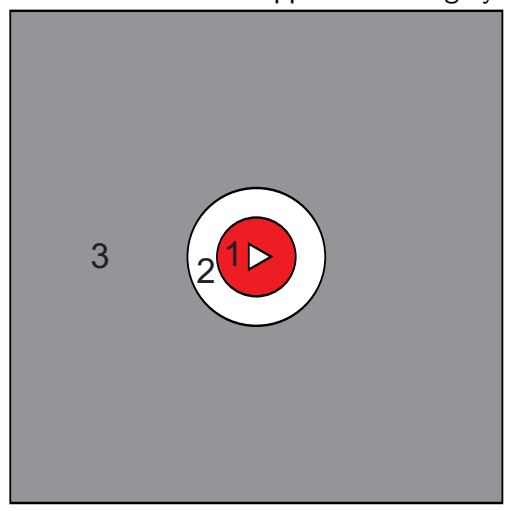

Figure 4 Scheme of the tool.

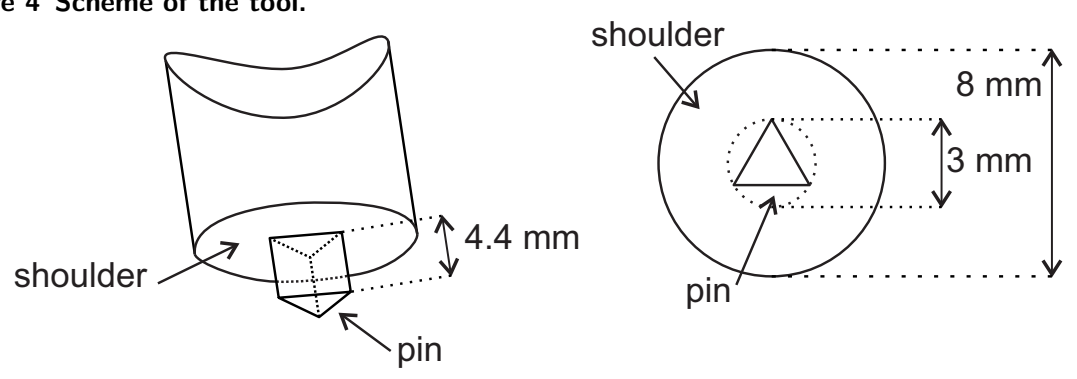


Figure 5 Scheme of the model with the initial position of the control point and the control line.

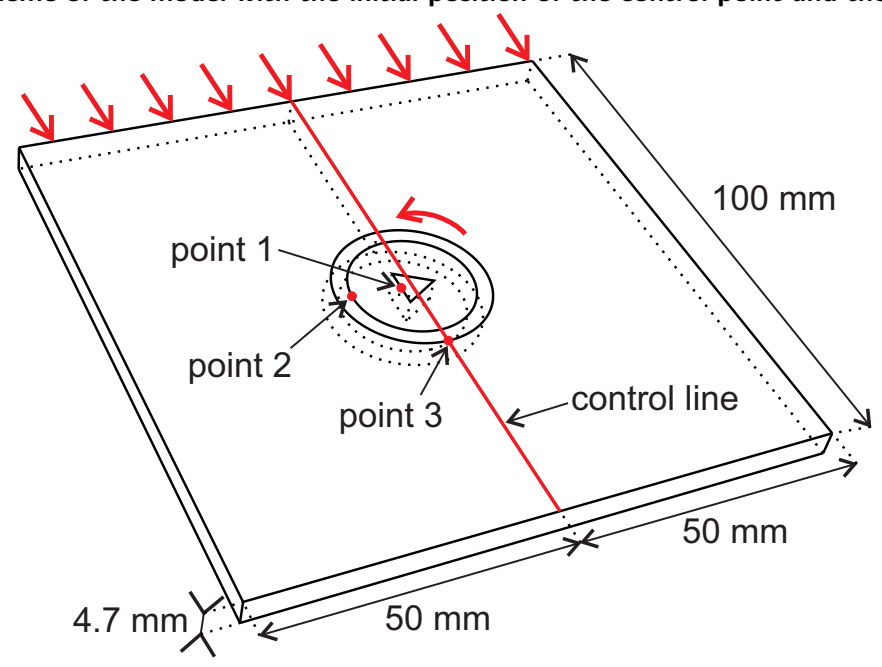

Figure 6 Evolution of the pressure and the temperature computed by the two models at the control point 1 (rotating with the tool). The rotation speed of the tool is 40 RPM and the initial position of this point is defined in Figure 5.
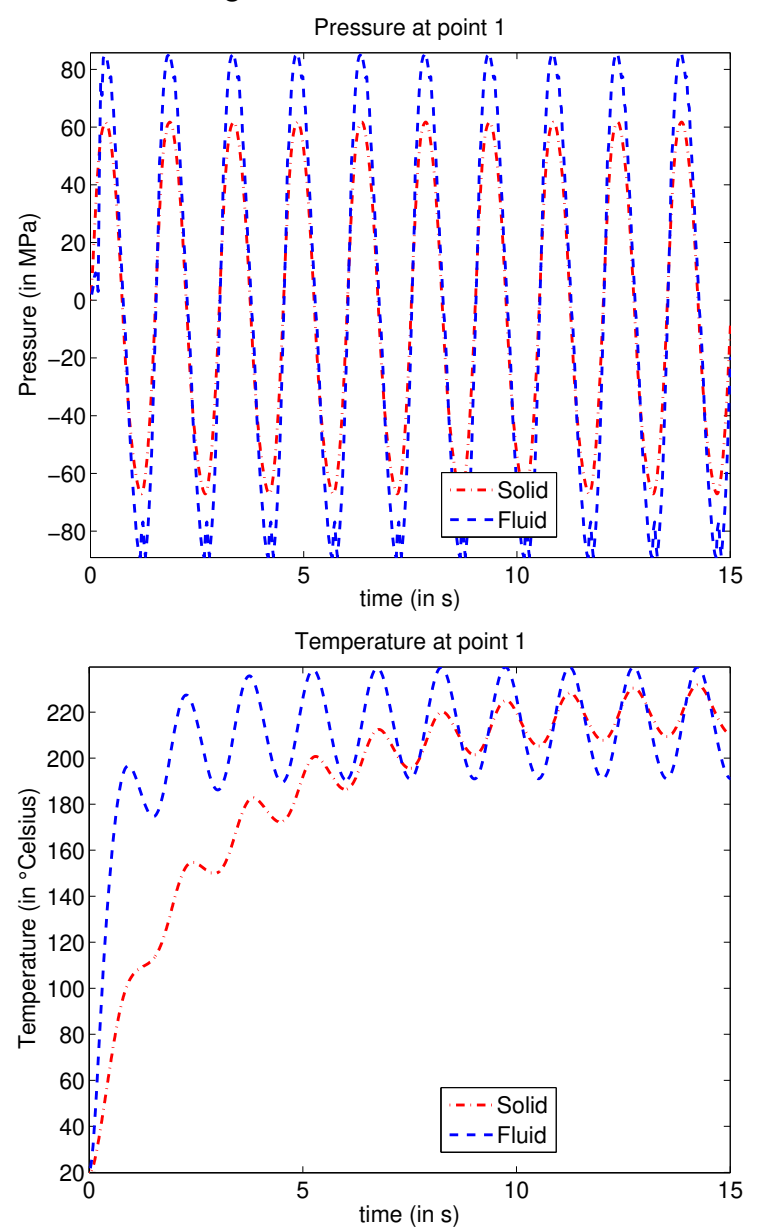


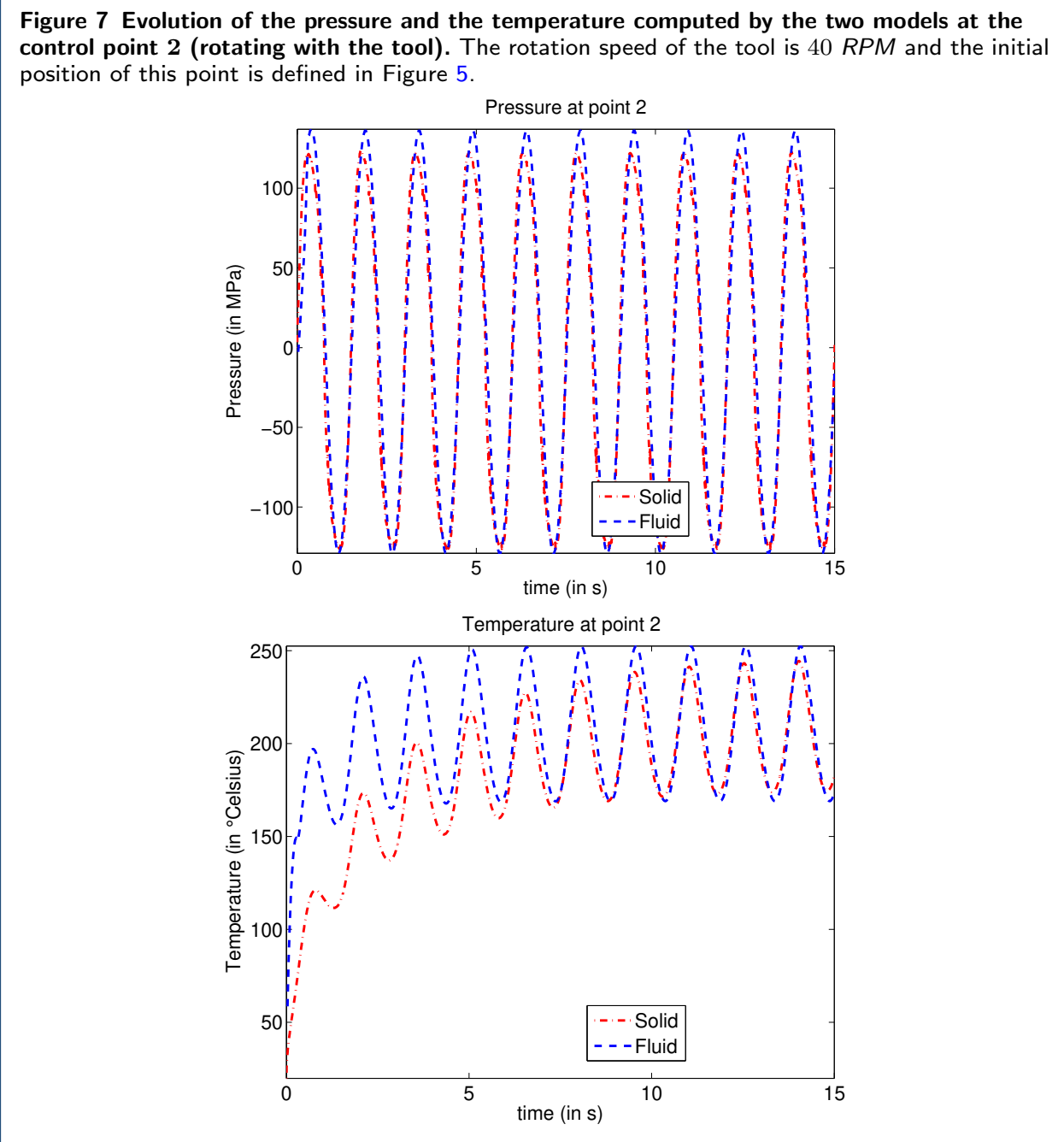


Figure 8 Evolution of the pressure and the temperature computed by the two models at the control point 3 (fixed in space). The rotation speed of the tool is 40 RPM and the initial position of this point is defined in Figure 5.
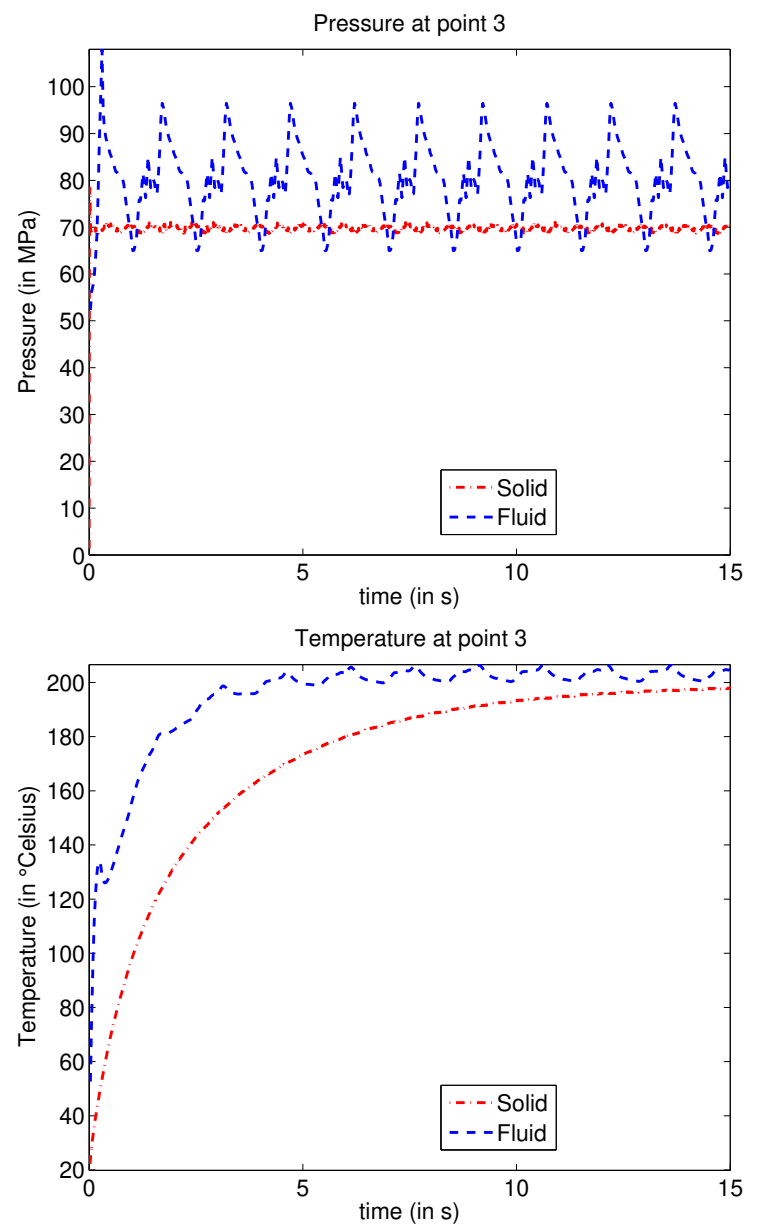
Figure 9 Evolution of the pressure and the temperature computed by the two models along the control line at the end of the simulation (i.e. after $15 \mathrm{~s}$ ). The rotation speed of the tool is $40 R P M$ and the line is defined in Figure 5.
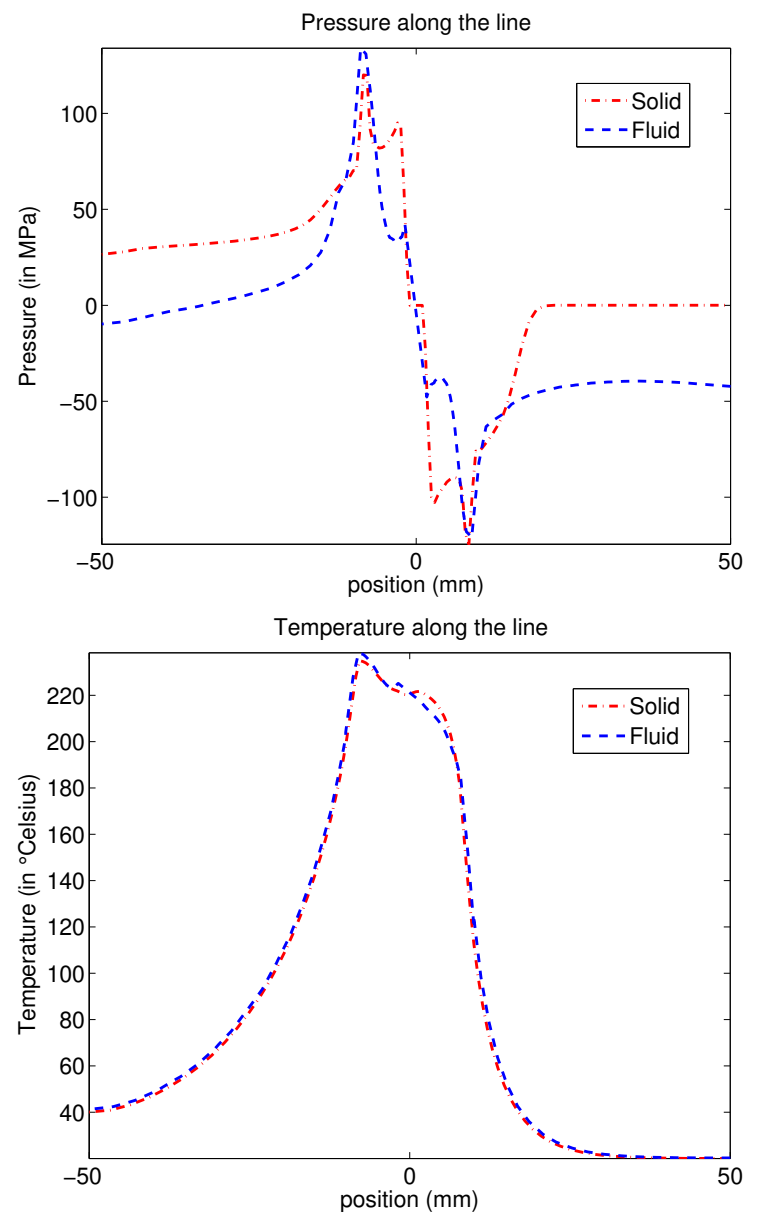
Figure 10 Evolution of the pressure and the temperature computed by the two models at the control point 1 (rotating with the tool). The rotation speed of the tool is $100 R P M$ and the initial position of this point is defined in Figure 5.
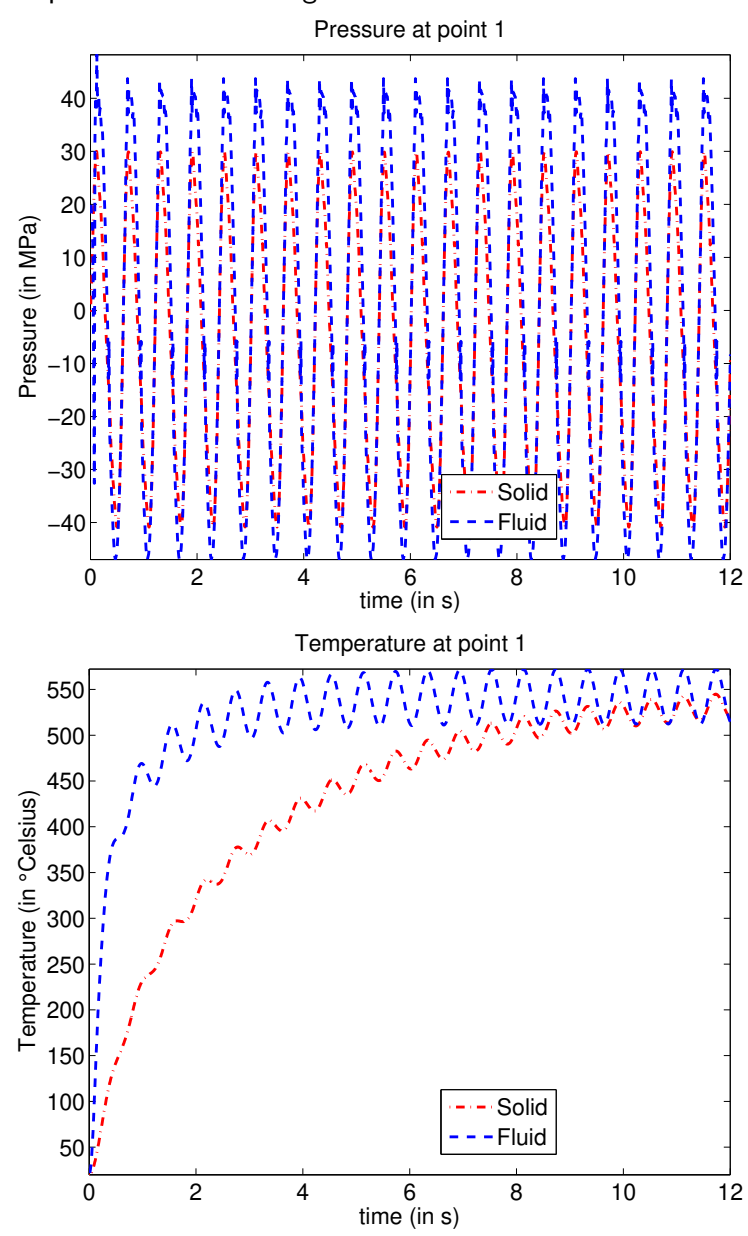
Figure 11 Evolution of the pressure and the temperature computed by the two models at the control point 2 (rotating with the tool). The rotation speed of the tool is $100 R P M$ and the initial position of this point is defined in Figure 5.
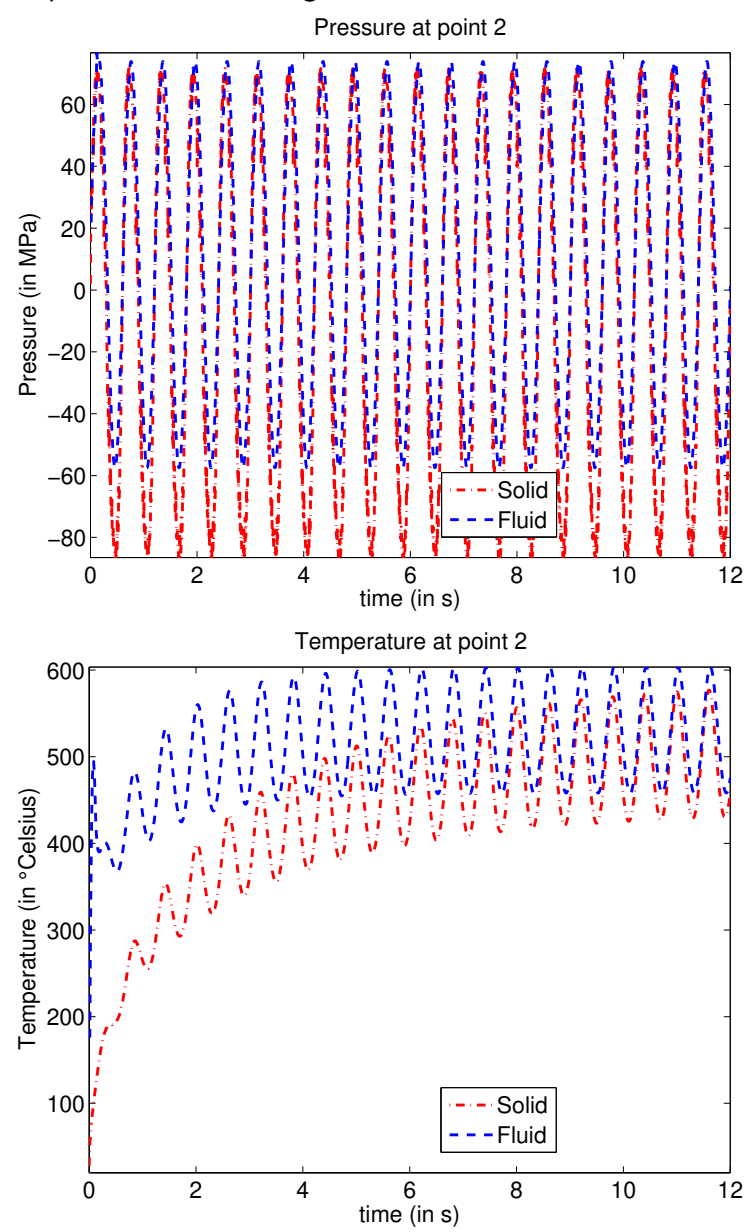
Figure 12 Evolution of the pressure and the temperature computed by the two models at the control point 3 (fixed in space). The rotation speed of the tool is 100 RPM and the initial position of this point is defined in Figure 5.
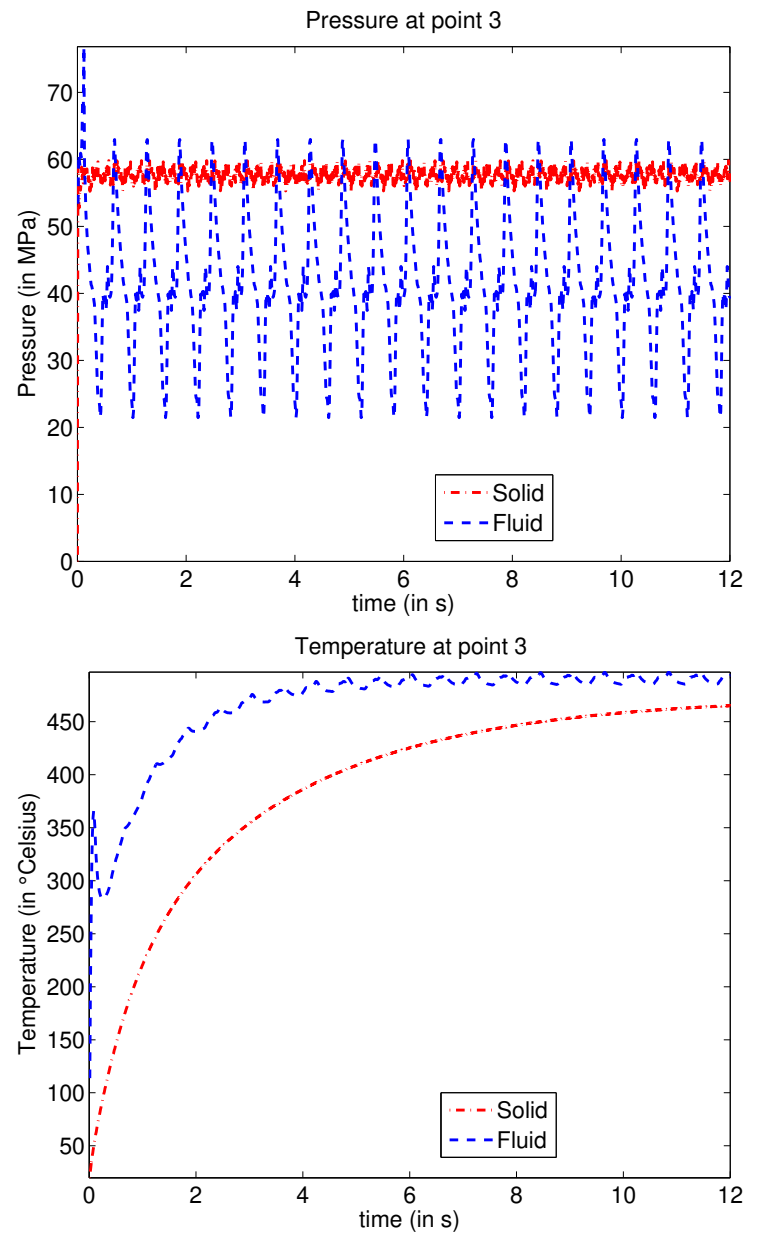
Figure 13 Evolution of the pressure and the temperature computed by the two models along the control line at the end of the simulation (i.e. after $12 \mathrm{~s}$ ). The rotation speed of the tool is $100 R P M$ and the line is defined in Figure 5.
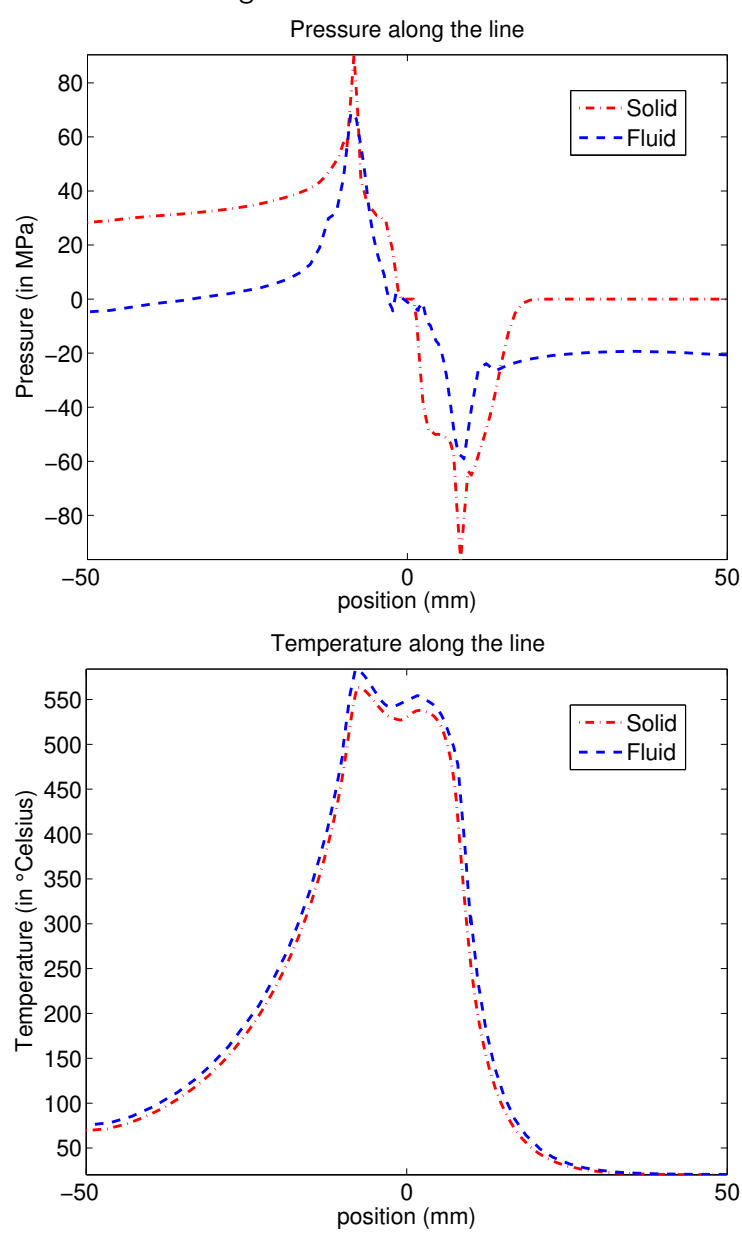